\title{
Gram-Scale Synthesis of Bimetallic ZIFs and Their Thermal Conversion to Nanoporous Carbon Materials
}

\author{
Freddy Marpaung ${ }^{1,2,+}$, Teahoon Park ${ }^{3,+}{ }^{+}$, Minjun Kim ${ }^{4,+}$, Jin Woo $\mathrm{Yi}^{3}$, Jianjian Lin ${ }^{2}$, \\ Jie Wang ${ }^{5}$, Bing Ding ${ }^{5}$, Hyunsoo Lim ${ }^{4}{ }^{\circledR}$, Konstantin Konstantinov ${ }^{1}{ }^{\circledR}$, Yusuke Yamauchi ${ }^{2,4,5}$, \\ Jongbeom $\mathrm{Na}^{2,4,5, *}$ and Jeonghun $\mathrm{Kim}^{2,6, *}$ \\ 1 Australian Institute for Innovative Materials (AIIM), University of Wollongong, Squires Way, North \\ Wollongong, NSW 2500, Australia; freddy.marpaung@bppt.go.id (F.M.); konstan@uow.edu.au (K.K.) \\ 2 Key Laboratory of Eco-Chemical Engineering, College of Chemistry and Molecular Engineering, Qingdao \\ University of Science and Technology, Qingdao 266042, China; jianjian_lin@qust.edu.cn (J.L.); \\ y.yamauchi@uq.edu.au (Y.Y.) \\ 3 Carbon Composite Department, Composites Research Division, Korea Institute of Materials Science (KIMS), \\ 797, Changwon-daero, Seongsan-gu, Changwon-si 51508, Gyeongsangnam-do, Korea; \\ thpark@kims.re.kr (T.P.); yjw0628@kims.re.kr (J.W.Y.) \\ 4 School of Chemical Engineering and Australian Institute for Bioengineering and Nanotechnology (AIBN), \\ The University of Queensland, Brisbane, QLD 4072, Australia; minjun.kim@uq.edu.au (M.K.); \\ h.lim@uq.edu.au (H.L.) \\ 5 International Research Center for Materials Nanoarchitechtonics (WPI-MANA), National Institute for \\ Materials Science (NIMS), 1-1 Namiki, Tsukuba, Ibaraki 305-0044, Japan; WANG.Jie@nims.go.jp (J.W.); \\ bingding@nuaa.edu.cn (B.D.) \\ 6 Department of Chemistry, Kookmin University, 77 Jeongneung ro, Seongbuk gu, Seoul 02707, Korea \\ * Correspondence: j.na@uq.edu.au (J.N.); jeonghunkim@kookmin.ac.kr (J.K.) \\ + These authors contributed equally to this work.
}

Received: 11 November 2019; Accepted: 13 December 2019; Published: 17 December 2019

\begin{abstract}
The hybrid metal-organic frameworks (MOFs) with different $\mathrm{Zn}^{2+} / \mathrm{Co}^{2+}$ ratios are synthesized at room temperature with deionized water as the solvent. This use of deionized water can increase the yield of hybrid MOFs (up to 65-70\%). After the pyrolysis, the obtained nanoporous carbons (NPCs) show a decrease in the surface area, in which the highest surface area is $655 \mathrm{~m}^{2} \mathrm{~g}^{-1}$. The as-prepared NPCs are subjected to activation with $\mathrm{KOH}$ in order to increase their surface area and convert cobalt nanoparticles (Co NPs) to Co oxides. These activated carbons are applied to electrical double-layer capacitors (EDLCs) and pseudocapacitors due to the presence of $\mathrm{CoO}$ and $\mathrm{Co}_{3} \mathrm{O}_{4}$ nanoparticles in the carbon framework, leading to significantly enhanced specific capacitance as compared to that of pristine NPCs. This synthetic method can be utilized in future research to enhance pseudocapacitance further while maintaining the maximum surface area of the carbon materials.
\end{abstract}

Keywords: hybrid MOFs; nanoporous carbon; microporous; activated carbon; capacitor

\section{Introduction}

Continuous consumption of fossil fuels has imposed a negative effect on the environment by accelerating global warming emissions and air pollution. To relieve these environmental stresses, researchers have put great efforts into developing renewable energy sources, including solar energy, wind power energy, geothermal energy, etc. [1-7]. Such energy supply, however, is not yet sufficiently stable, and its efficiency is greatly influenced by external conditions. Therefore, it is essential to establish an effective and efficient energy storage system to allow renewable energy to be stored for later use [8-10]. 
Together with secondary batteries, supercapacitors are one of the most commonly utilized types of energy storage devices [11-13]. Supercapacitors are classified into electrical double-layer capacitors (EDLCs) and pseudocapacitors based on their distinctive charge storage mechanisms. In EDLCs, electrical charge is stored via physical adsorption/desorption of electrolyte ions on the interfaces of electrode/electrolyte through electrostatic attractions. Pseudocapacitors, on the other hand, exploit a surface redox reaction to store electrical charge. EDLCs have gained significant attention due to their outstanding electrochemical advantages, including high power densities, fast charge/discharge as well as superior cyclability. However, their poor energy density, low voltage per cell, high rate of self-discharge, and costly production remain as major challenges to achieve more advanced and functional supercapacitors.

Metal-organic frameworks (MOFs) are formed via coordination bonding between metal ions and organic ligands, which often results in highly ordered porous structures [14-16]. Due to the rich content of organic ligands, serving as carbon-sources, MOFs can be utilized as promising carbon precursors to give rise to highly functional carbon materials [17-21]. MOF-derived carbons have been investigated for a broad range of electrochemical applications due to their intrinsic characteristics such as high surface area, controlled chemical functionality, and highly uniform pore sizes. A class of MOFs known as zeolitic imidazolate frameworks (ZIFs) recently have been synthesized in various organic solvents such as methanol, N,N-dimethylformamide (DMF), N,N-diethylformamide (DEF), and dimethyl sulfoxide (DMSO) [22-25]. Recently, Kim et al. have successfully synthesized hybrid ZIFs with dodecahedral shape by using methanol as the organic solvent [26]. The obtained hybrid ZIFs in methanol, however, show a relatively low yield. Moreover, methanol is toxic, highly flammable, and costly, like other organic solvents commonly used for MOF synthesis.

Interestingly, the electrochemical properties of MOF-derived carbons can be improved by incorporating metal, metal oxide, or metal sulfide nanoparticles onto the carbon surface [27]. For example, Kim et al. successfully synthesized hybrid Co/Zn-ZIF-derived nanoporous carbons (NPCs), which were functionalized with a high content of $\mathrm{Co}_{3} \mathrm{O}_{4}$ nanoparticles (NPs) after oxidation [28]. Due to the presence of both EDLC and pseudocapacitance, the obtained NPCs show a high specific capacitance of up to $545 \mathrm{~F} \mathrm{~g}^{-1}$ and good electrochemical stability with nearly $70 \%$ capacity retention after 10,000 charge-discharge cycles. Such ZIF-8/ZIF-67 hybrid ZIF-derived carbons are reported to exhibit a higher graphitic degree than ZIF-8 derived carbons and to allow functionalization of carbon with Co species. In this study, we synthesize hybrid ZIF-8/ZIF-67-derived carbons with different Zn to $\mathrm{Co}$ ratios and activate the carbons with $\mathrm{KOH}$ [28]. The $\mathrm{KOH}$ activation of hybrid ZIF-derived carbons allows avoiding the large loss of specific surface area while obtaining $\mathrm{CoO}$ and $\mathrm{Co}_{3} \mathrm{O}_{4}$ in the carbon matrix. The existing $\mathrm{CoO}$ and $\mathrm{Co}_{3} \mathrm{O}_{4}$ act as the surface redox-active sites, giving rise to both pseudocapacitance and EDLC.

\section{Methods}

\subsection{Synthesis of Hybrid MOFs Having Bimetallic Ions $\left(\mathrm{Zn}^{2+} / \mathrm{Co}^{2+}\right)$ with Different Molar Ratios}

Hybrid ZIFs were synthesized in three different $\mathrm{Zn}^{2+}$ to $\mathrm{Co}^{2+}$ molar ratios (3:1, 1:1, and 1:3). For MOF-3:1, $1.125 \mathrm{~g}$ of $\mathrm{Zn}\left(\mathrm{CH}_{3} \mathrm{CO}_{2}\right)_{2} \cdot 2 \mathrm{H}_{2} \mathrm{O}$ and $0.425 \mathrm{~g}$ of $\mathrm{Co}\left(\mathrm{CH}_{3} \mathrm{CO}_{2}\right)_{2} \cdot 4 \mathrm{H}_{2} \mathrm{O}$ were dissolved in $50 \mathrm{~mL}$ deionized water. For MOF-1:1, $0.750 \mathrm{~g}$ of $\mathrm{Zn}\left(\mathrm{CH}_{3} \mathrm{CO}_{2}\right)_{2} \cdot 2 \mathrm{H}_{2} \mathrm{O}$ and $0.850 \mathrm{~g}$ of $\mathrm{Co}\left(\mathrm{CH}_{3} \mathrm{CO}_{2}\right)_{2} \cdot 4 \mathrm{H}_{2} \mathrm{O}$ were dissolved in $50 \mathrm{~mL}$ deionized water. For MOF-1:3, $0.375 \mathrm{~g}$ of $\mathrm{Zn}\left(\mathrm{CH}_{3} \mathrm{CO}_{2}\right)_{2} \cdot 2 \mathrm{H}_{2} \mathrm{O}$ and $1.276 \mathrm{~g}$ of $\mathrm{Co}\left(\mathrm{CH}_{3} \mathrm{CO}_{2}\right)_{2} \cdot 4 \mathrm{H}_{2} \mathrm{O}$ were dissolved in $50 \mathrm{~mL}$ deionized water. $5.6 \mathrm{~g}$ of 2-methyl imidazole was dissolved in separate $50 \mathrm{~mL}$ deionized water and then mixed with each sample metal solution. After stirring for $10 \mathrm{~min}$, the resulting solution was kept at room temperature for $24 \mathrm{~h}$. As-synthesized hybrid ZIFs were thoroughly washed several times with deionized water and dried at $60{ }^{\circ} \mathrm{C}$. The resulting MOFs were denoted as MOF-3:1, MOF-1:1, and MOF-1:3, respectively. The same experimental procedures were followed with methanol as a solvent. 


\subsection{Carbonization of Hybrid ZIFs}

The ZIF powders were carbonized at a temperature of $800{ }^{\circ} \mathrm{C}$ for $3 \mathrm{~h}$ under nitrogen with a heating rate of $5{ }^{\circ} \mathrm{C} \mathrm{min}^{-1}$. The obtained carbon particles were washed several times with deionized water to increase the $\mathrm{pH}$ close to 7.0. The resulting NPCs were denoted as NPC-3:1, NPC-1:1, and NPC-1:3, respectively.

\subsection{Activation of NPCs}

The NPCs were immersed in concentrated $\mathrm{KOH}$ solution and dried at room temperature prior to the pyrolysis process. The obtained powders were pyrolyzed at $800^{\circ} \mathrm{C}$ under nitrogen with a heating rate of $5{ }^{\circ} \mathrm{C} \mathrm{min}^{-1}$, and then they were washed with $1 \mathrm{M} \mathrm{HCl}$ solution. The obtained samples were denoted as AC-3:1, AC-1:1, and AC-1:3, respectively.

\subsection{Characterization}

Field emission-scanning electron microscopy (FE-SEM) was operated with a JSM-7100F microscope (JEOL Ltd., Tokyo, Japan) at $10.0 \mathrm{kV}$. Transmission electron microscopy (TEM) and scanning TEM (STEM) were operated at $100 \mathrm{kV}$ by HT7700 (Hitachi Ltd., Tokyo, Japan). Powder X-ray diffraction (PXRD, D8 Advance, Bruker, Billerica, MA, USA) was used to study crystal structures of materials with $\mathrm{Cu}-\mathrm{K} \alpha$ radiation at $40 \mathrm{kV}$ and $40 \mathrm{~mA}$. The elemental composition and the electric structure were investigated by Kratos Axis Ultra photoelectron spectrometer (Kratos Analytical Inc., Manchester, $\mathrm{UK})$ using mono $\mathrm{Al} \mathrm{K} \alpha(1486.6 \mathrm{eV}) \mathrm{X}$-rays. $\mathrm{N}_{2}$ adsorption-desorption isotherms were measured by Quadrasorb SI (Quantachrome Instrument, Boynton Beach, FL, USA). The specific surface area and pore size distribution were obtained by using the Brunauer-Emmett-Teller (BET) method and the non-localized density functional theory (NLDFT) method, respectively.

\subsection{Electrochemical Measurement}

Electrochemical measurements were taken with a CHI660E electrochemical workstation $(\mathrm{CH}$ Instruments, Inc., Austin, TX, USA) at room temperature. Three-electrode cell with Pt counter electrode, $\mathrm{Hg} / \mathrm{HgO}$ reference electrode, and $6 \mathrm{M} \mathrm{KOH}$ electrolyte was used. The working electrode solution was prepared with the as-prepared NPC and AC samples, carbon black and PVDF at 8:1:1 weight ratio in $100 \mu \mathrm{L}$ of N-methyl-2-pyrrolidone (NMP). The solution was thoroughly mixed by ultrasonication before loading onto $1 \mathrm{~cm} \times 1 \mathrm{~cm}$ graphite electrode. The working electrode was then vacuum dried at $60{ }^{\circ} \mathrm{C}$ overnight. Cyclic voltammetry was measured at multiple scan rates of 1, 5, 10, 20, 50, 100, 200, 300 , and $500 \mathrm{mV} \mathrm{s}^{-1}$.

\section{Results and Discussion}

SEM images of hybrid bimetallic MOFs (MOF-3:1, MOF-1:1, and MOF-1:3) show typical dodecahedral shape with particle sizes varying from 1 to $3 \mu \mathrm{m}$ (Figure 1a-c). Wide-angle XRD patterns of MOFs synthesized in deionized water show a highly similar crystal structure with MOFs prepared in methanol while the yield (\%) of hybrid MOFs in the water-based synthesis can be increased to more than five times higher than that in methanol-based synthesis (Figure 2). Hence, the water-based synthetic strategy can vastly improve the final yield of hybrid MOFs without changing the MOF crystal structure. According to nitrogen adsorption-desorption isotherms, three types of hybrid MOFs show type I isotherm with a rapid uptake of $\mathrm{N}_{2}$ at low relative pressure, clearly indicating a characteristic of microporous materials. Table 1 summarizes the specific surface area (SSA) and the pore volume of hybrid MOF-3:1, MOF-1:1, and MOF-1:3, respectively. 

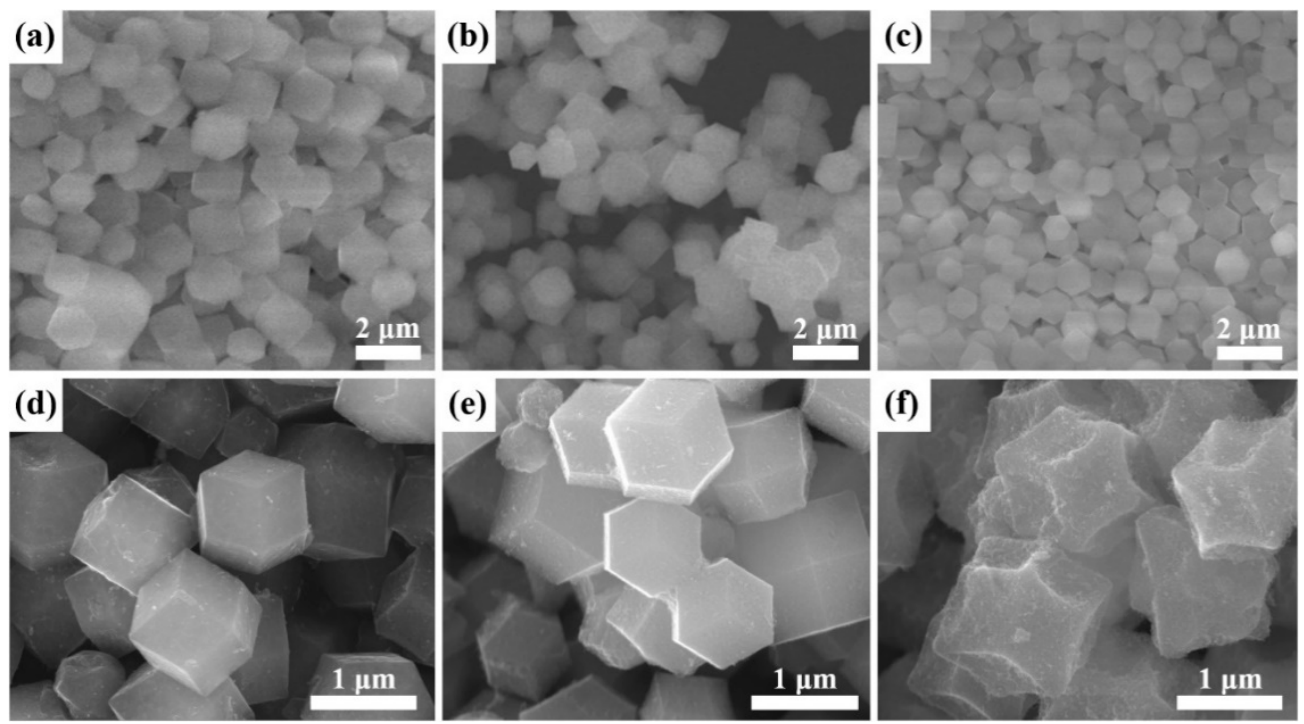

Figure 1. Scanning electron microscopy (SEM) images of (a) metal-organic frameworks (MOF)-3:1, (b) MOF-1:1, (c) MOF-1:3, (d) nanoporous carbons (NPC)-3:1, (e) NPC-1:1 and (f) NPC-1:3, respectively.
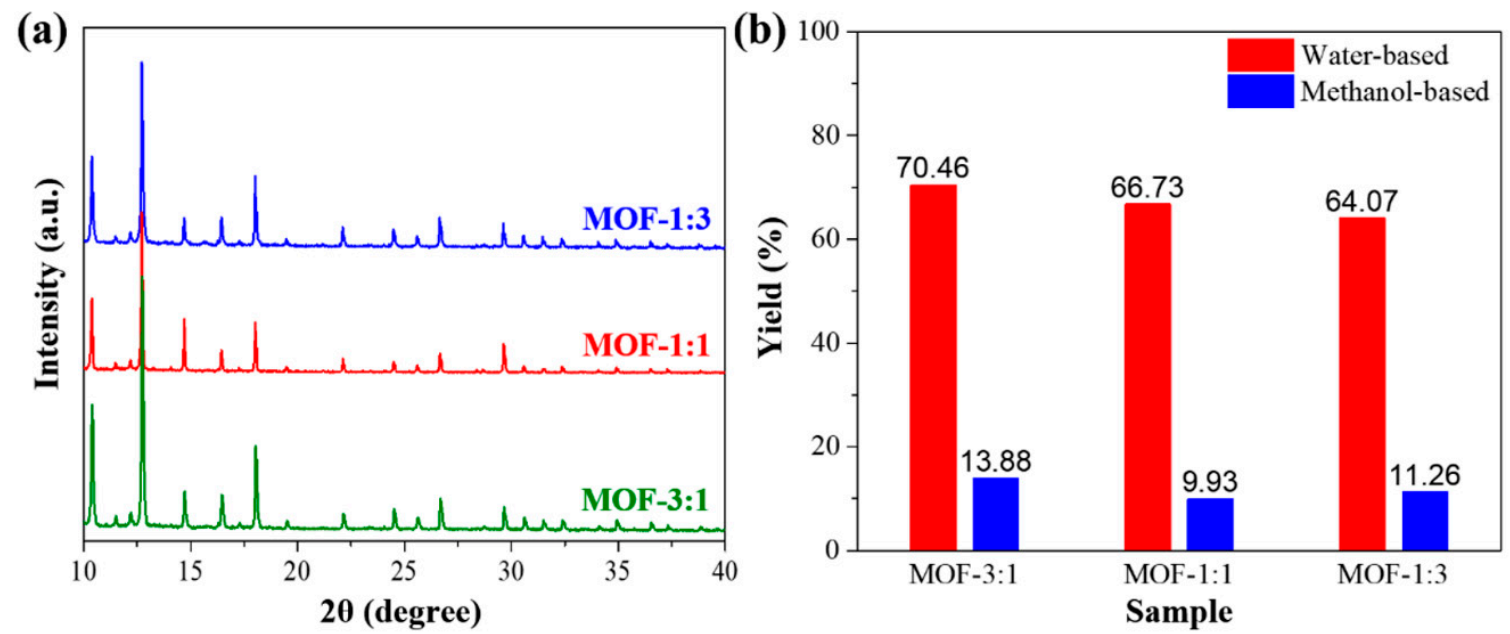

Figure 2. (a) Wide-angle X-ray diffraction (XRD) of MOF-3:1, MOF-1:1, and MOF-1:3. (b) Comparison of yield (\%) of MOF-3:1, MOF-1:1, and MOF-1: between water-based synthesis and methanol-based synthesis. The yield is calculated based on the total mole of both $\mathrm{Zn}$ and Co metal species.

Table 1. Summary of surface area and pore volume of ACs.

\begin{tabular}{ccc}
\hline Sample & Surface Area $\left(\mathbf{m}^{\mathbf{2}} \mathbf{g}^{\mathbf{- 1}}\right)$ & Pore Volume $\left(\mathbf{c m}^{\mathbf{3}} \mathbf{g}^{-\mathbf{1}}\right)$ \\
\hline MOF-3:1 & 1393 & 0.126 \\
MOF-1:1 & 1414 & 0.124 \\
MOF-1:3 & 1417 & 0.103 \\
NPC-3:1 & 655 & 0.238 \\
NPC-1:1 & 551 & 0.388 \\
NPC-1:3 & 413 & 0.579 \\
AC-3:1 & 423 & 0.416 \\
AC-1:1 & 205 & 0.335 \\
AC-1:3 & 224 & 0.453 \\
\hline
\end{tabular}

The NPC particles after carbonization maintain a typical morphology with dodecahedral structures (Figure 1d-f), similar to the original morphology of the hybrid MOFs (Figure 1). It is observed that 
NPC-3:1 and NPC-1:1 show a smooth and well-defined surface morphology, while NPC-1:3 shows a certain level of deformation. Interestingly, TEM images of NPCs show the formation of carbon nanotubes (CNTs) on the surface after the pyrolysis, as indicated by arrows (Figure 3a-c). The Co NPs on the carbon matrix are known to act as catalytic sites for the growth of graphitic CNTs [26,29]. It is important to note that the extent of CNT formation on NPCs is greater for NPCs with the higher molar ratio of Co of their parent MOFs.
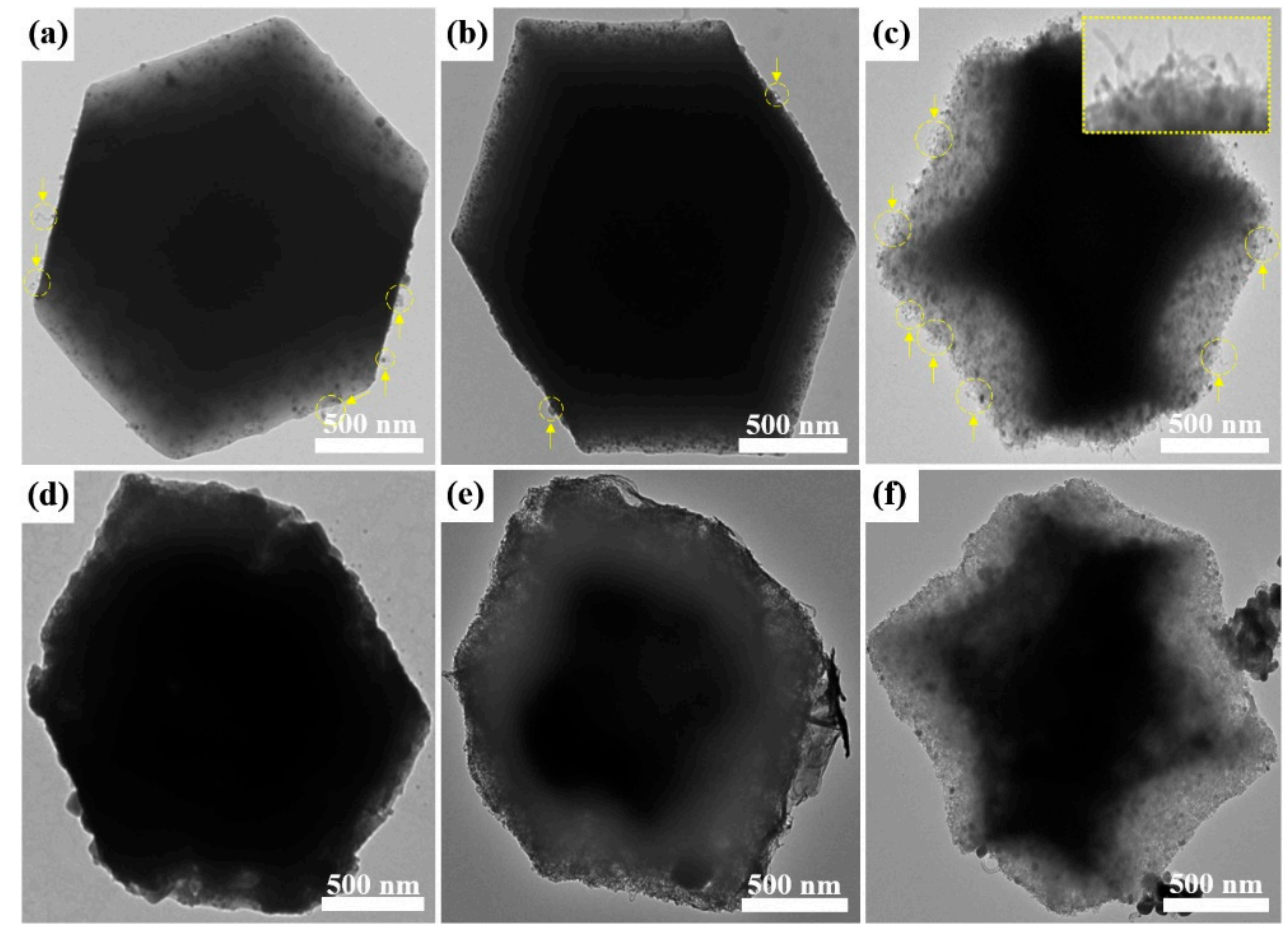

Figure 3. Transmission electron microscopy (TEM) images of (a) NPC-3:1, (b) NPC-1:1, (c) NPC-1:3, (d) activated carbon (AC)-3:1, (e) AC-1:1, and (f) AC-1:3, respectively. Yellow arrows in (a-c) indicate the presence of carbon nanotubes (CNTs). Inset figure in (c) shows the enlarged image of CNTs on the surface of the AC-1:3.

The wide-angle XRD patterns of NPC samples are shown in Figure 4a. Two typical carbon peaks are observable at around $26^{\circ}$, which corresponds to the (002) peak of graphitic carbon. When the Co content is higher in the starting MOFs, the (111), (200), and (220) peaks are more obvious. The average size of the Co NPs was calculated from the broadening of peaks using the Scherrer equation. The average sizes of the Co NPs are around 4.0, 4.6, and $6.3 \mathrm{~nm}$, for NPC-3:1, NPC-1:1, and NPC-1:3, respectively. From the nitrogen adsorption-desorption isotherms for NPC-3:1, NPC-1:1, and NPC-1:3, the SSA of the NPCs is $655 \mathrm{~m}^{2} \mathrm{~g}^{-1}$ (NPC-3:1), $551 \mathrm{~m}^{2} \mathrm{~g}^{-1}$ (NPC-1:1) and $413 \mathrm{~m}^{2} \mathrm{~g}^{-1}$ (NPC-1:3), while the pore volume is $0.238 \mathrm{~cm}^{3} \mathrm{~g}^{-1}$ (NPC-3:1), $0.388 \mathrm{~cm}^{3} \mathrm{~g}^{-1}$ (NPC-1:1), and $0.579 \mathrm{~cm}^{3} \mathrm{~g}^{-1}$ (NPC-1:3). These surface areas are relatively lower in comparison with ZIF-8-derived carbon [30,31]. The results show that the SSA is decreased with the increase in cobalt content. 

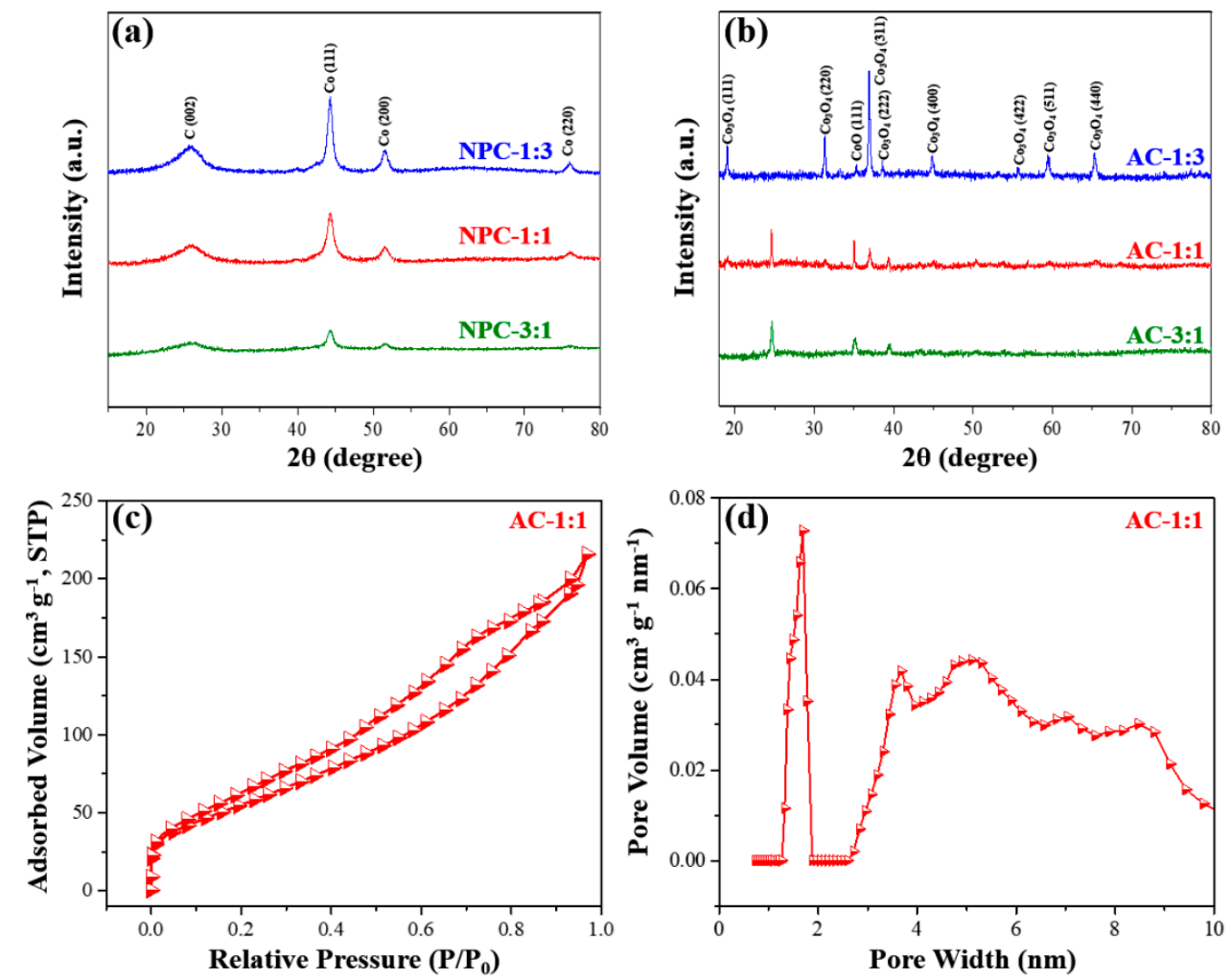

Figure 4. Wide-angle XRD for (a) NPC-1:3, NPC-1:1, and NPC-3:1 (before activation) and (b) AC-1:3, AC-1:1, AC-3:1 (after activation). The peaks for cobalt and cobalt oxides are denoted. (c) $\mathrm{N}_{2}$ adsorption-desorption isotherms for AC-1:1 and (d) pore size distribution of AC-1:1.

To understand the surface chemical composition and valence states of as-synthesized NPCs, we carefully analyzed the XPS data. As shown in Figure 5, it is revealed that all the samples include carbon, cobalt, oxygen, and nitrogen. Most of the $\mathrm{Zn}$ content can be removed/evaporated at high-temperature carbonization process $[30,31]$. From the XPS analysis (Table 2), the proportion of carbon from NPC-3:1 to NPC-1:3 were calculated to be 83.1 at.\% (NPC-3:1), 89.5 at.\% (NPC-1:1), 93.5 at.\% (NPC-1:3), respectively. From Figure $5 c$, it is found that the Co metal surface is slightly oxidized, which is not detected by the above wide-angle XRD measurement (Figure 4a). 

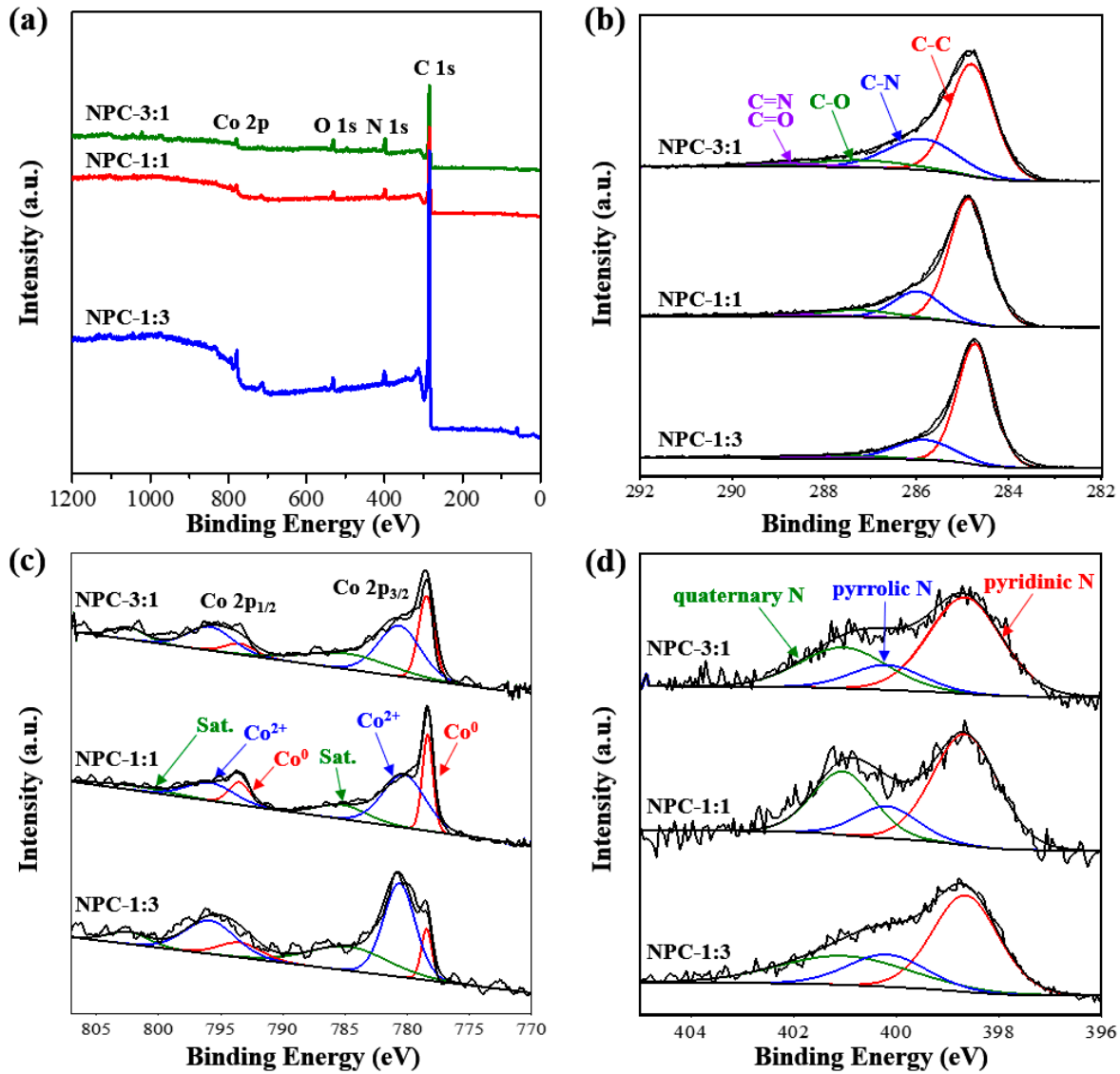

Figure 5. XPS spectra of NPCs. (a) Survey X-ray photoelectron spectroscopy (XPS) spectra, (b) C 1s XPS spectra, (c) Co 2p XPS spectra, and (d) O 1s XPS spectra, respectively.

Table 2. XPS elemental analysis data of various NPC and AC samples.

\begin{tabular}{cccccc}
\hline \multicolumn{7}{c}{ Elemental Analysis (at.\%) } \\
\hline Sample & Zn & Co & C & N & O \\
\hline NPC-3:1 & 0.37 & 0.70 & 83.1 & 10.8 & 5.08 \\
NPC-1:1 & - & 1.11 & 89.5 & 6.42 & 3.00 \\
NPC-1:3 & - & 0.94 & 93.5 & 3.70 & 1.84 \\
AC-3:1 & 0.05 & 2.50 & 84.03 & 3.92 & 9.50 \\
AC-1:1 & - & 5.28 & 78.63 & 2.36 & 13.73 \\
AC-1:3 & 0.01 & 3.35 & 80.30 & 6.05 & 10.28 \\
\hline
\end{tabular}

Figure $3 \mathrm{~d}-\mathrm{f}$ clearly shows the effect of $\mathrm{KOH}$ activation on the morphology of NPCs. Basically, the original NPC shapes remain, but the surface of ACs tend to become much rougher compared to their respective NPCs due to chemical etching by $\mathrm{KOH}$. Wide-angle XRD patterns of AC samples show co-existence of $\mathrm{CoO}$ and $\mathrm{Co}_{3} \mathrm{O}_{4}$ as well as $\mathrm{Co}$ (Figure $4 \mathrm{~b}$ ), indicating that the original $\mathrm{Co}$ is partially or fully oxidized to $\mathrm{CoO}$ and $\mathrm{Co}_{3} \mathrm{O}_{4}$ during the $\mathrm{KOH}$ activation process. The SSA and pore volume for $\mathrm{ACs}$ are characterized by $\mathrm{N}_{2}$ adsorption-desorption isotherms (Figure $4 \mathrm{c}-\mathrm{d}$ and Figure S1). According to Table 1, three AC samples show to reduce the SSAs compared to their NPC samples. This observation can be partly attributed to the increased weight density of ACs due to the formation of $\mathrm{Co}_{3} \mathrm{O}_{4} \mathrm{NPs}$ and the reduction of carbon amount. The element compositional ratios of ACs from survey XPS (Figure 6 and Table 2) show higher compositional content of Co with respect to that of $C$ in comparison to the NPCs. 


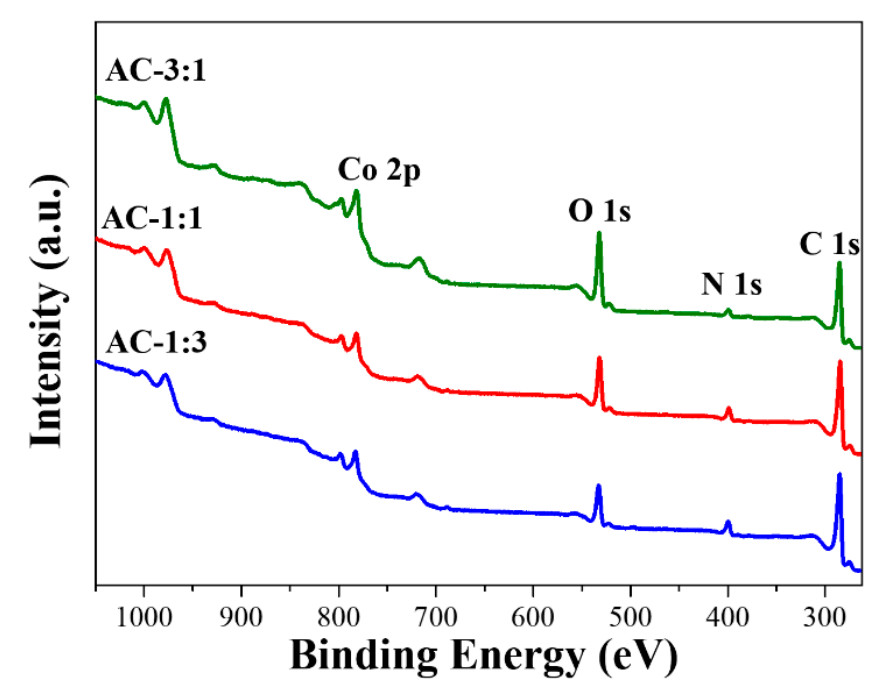

Figure 6. XPS survey for AC-3:1, AC-1:1, and AC-1:3, respectively.

The electrochemical performance of the as-prepared NPC and AC samples were evaluated from cyclic voltammetry (CV), as shown in Figure 7. The CV of all AC samples clearly shows the co-existence of EDLC and pseudocapacitance, whereas only EDLC is mainly observed in the CV of NPC samples. According to wide-angle XRD patterns (Figure $4 \mathrm{~b}$ ), the redox activity of the ACs can be attributed to the presence of $\mathrm{CoO}$ or $\mathrm{Co}_{3} \mathrm{O}_{4} \mathrm{NPs}$, which are formed via partial or full oxidation of Co NPs in the AC samples. The two cobalt oxide species are well-known for their distinctive pseudocapacitance [32]. However, there is no observable redox activity in AC-1:3, possibly due to the encapsulation of Co species within the carbon framework. This is further evidenced by our XPS elemental analysis showing lower Co content in AC-1:3 as compared to AC-3:1 and AC-1:1 (Table 2) [29]. Consequently, each AC sample exhibits a significantly enhanced specific capacitance at all scan rates $(1,5,10,20,50,100,200$, $300,500 \mathrm{mV} \mathrm{s}^{-1}$ ) as compared to their pristine NPC (Figure 8). After activation, the specific capacitance is clearly increased. Among samples prepared with different $\mathrm{Zn}^{2+}$ to $\mathrm{Co}^{2+}$ molar ratio, AC-1:1 exhibits the most superior specific capacitance over a broad range of scan rates. Especially at a higher scan rate, AC-1:1 exhibits the greatest specific capacitance among the three AC samples, indicating that AC-1:1 is highly electrochemically stable at a rapid scan rate (Figure 8). This is largely due to the optimized compositional ratio of $\mathrm{Co}$ and $\mathrm{O}$ of $\mathrm{AC}-1: 1$ originating from $\mathrm{CoO}$ and $\mathrm{Co}_{3} \mathrm{O}_{4} \mathrm{NPs}$ on the surface, thus giving rise to greater pseudocapacitance together with EDLC.
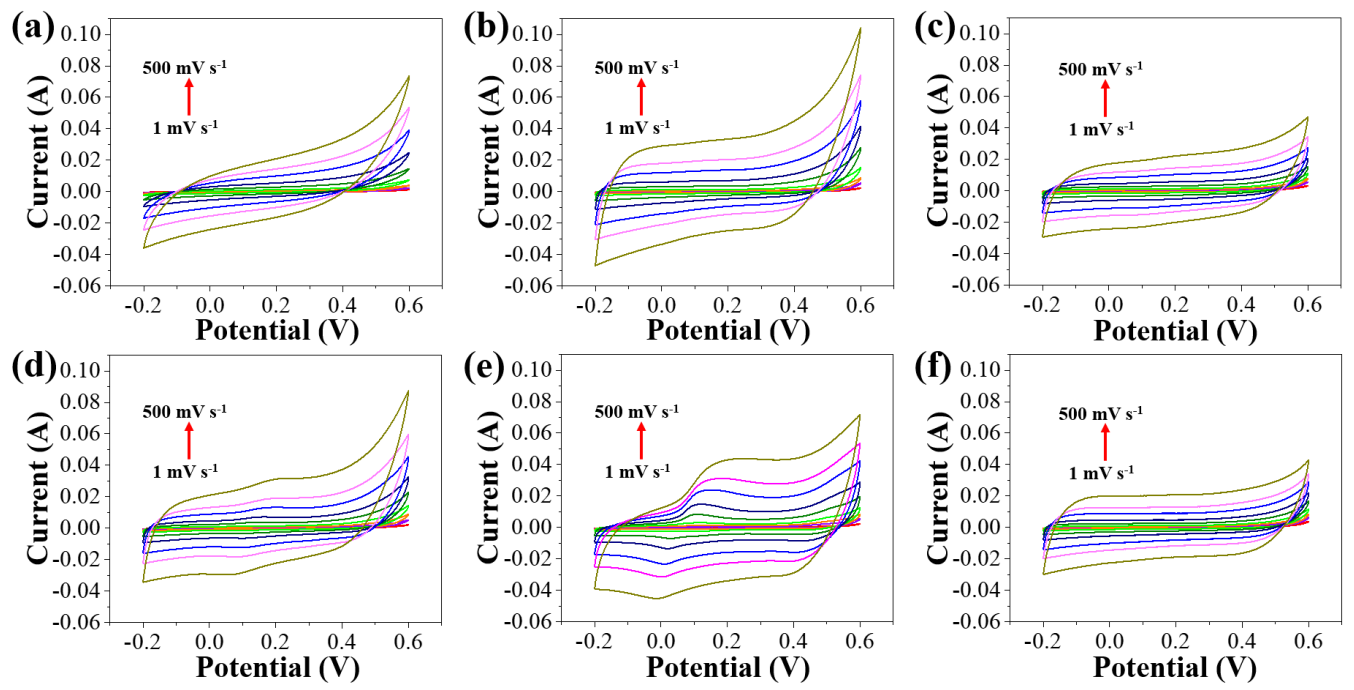

Figure 7. CVs for (a) NPC-3:1, (b) NPC-1:1, (c) NPC-1:3, (d) AC-3:1, (e) AC-1:1, and (f) AC-1:3. 
(a)

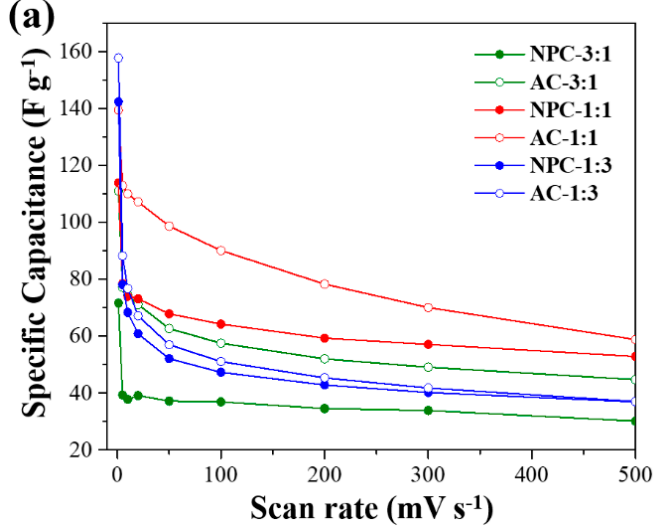

(b)

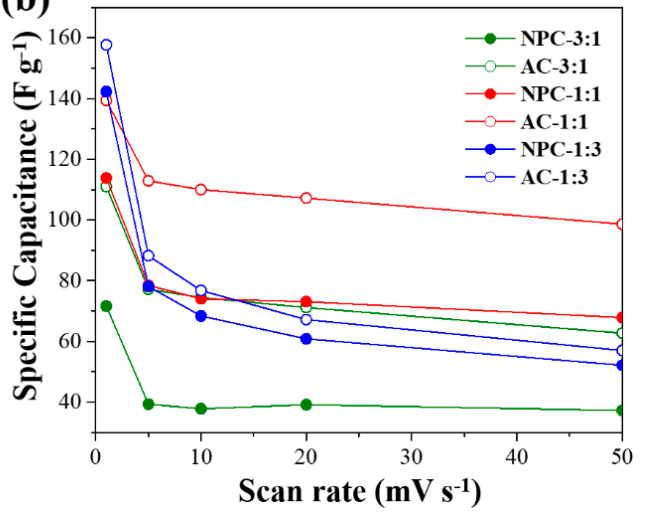

Figure 8. Specific capacitance at different scan rates at (a) 1, 5, 10, 20, 50, 100, 200, 300, and $500 \mathrm{mV} \mathrm{s}^{-1}$, (b) $1,5,10,20$, and $50 \mathrm{mV} \mathrm{s}^{-1}$.

\section{Conclusions}

Hybrid MOFs with different $\mathrm{Zn}^{2+} / \mathrm{Co}^{2+}$ ratios are synthesized at room temperature using water-based synthesis. The use of deionized water as a solvent allows a significantly increased yield of hybrid MOFs, where the maximum yield reaches around $65-70 \%$. The resulting hybrid MOFs show type-I isotherm, which is typical for microporous material with high SSA. After the pyrolysis process, the obtained NPCs show a decrease in surface area, in which the highest surface area is $655 \mathrm{~m}^{2}$ $\mathrm{g}^{-1}$ for NPC-3:1. It is also found that the CNTs content is significantly increased by increasing the Co content. The as-prepared NPCs are subsequently subjected to activation with $\mathrm{KOH}$ in order to increase their surface area and convert Co NPs to Co oxides. The resulting activated carbons (AC-1:3, 1:1 and 3:1) exhibit both EDLC and pseudocapacitance due to the presence of $\mathrm{CoO}$ and $\mathrm{Co}_{3} \mathrm{O}_{4}$ nanoparticles in the carbon framework, leading to significantly enhanced specific capacitance as compared to their pristine NPCs. Among the three AC samples, AC-1:1 shows stable electrochemical performance as its specific capacitance outcompetes that of other samples at all scan rates. The water-based synthetic method reported in this study is highly efficient and environmental-friendly. Furthermore, oxidation of Co NPs in hybrid MOFs using KOH activation process can be utilized in future research to maximize pseudocapacitance further while maintaining the maximum surface area of the carbon materials. Recently, many types of functional MOF-derived materials with different compositions have been reported by several groups [33-36]. Therefore, the optimal activation method reported here will be useful for further upgrading the material performance in the future.

Supplementary Materials: The following are available online at http://www.mdpi.com/2079-4991/9/12/1796/s1, Figure S1: $\mathrm{N}_{2}$ adsorption-desorption isotherms and pore size distribution for AC-1:3 and AC-3:1.

Author Contributions: Data curation-T.P.; Formal analysis-F.M. and M.K.; Funding acquisition-J.W.Y.; Methodology-J.L., J.W. and B.D.; Resources-K.K.; Supervision-Y.Y., J.N. and J.K.; Visualization-H.L.; Writing draft-F.M. and M.K.

Funding: This research was funded by the Principal Research Program (PNK5600) at the Korea Institute of Materials Science (KIMS).

Conflicts of Interest: The authors declare no conflict of interest.

\section{References}

1. Liu, M.; Johnston, M.B.; Snaith, H.J. Efficient planar heterojunction perovskite solar cells by vapour deposition. Nature 2013, 501, 395. [CrossRef] [PubMed]

2. Na, J.; Kim, Y.; Park, C.; Kim, E. Multi-layering of a nanopatterned $\mathrm{TiO}_{2}$ layer for highly efficient solid-state solar cells. NPG Asia Mater. 2015, 7, e217. [CrossRef]

3. Staffell, I.; Pfenninger, S. Using bias-corrected reanalysis to simulate current and future wind power output. Energy 2016, 114, 1224-1239. [CrossRef] 
4. Kumar, Y.; Ringenberg, J.; Depuru, S.S.; Devabhaktuni, V.K.; Lee, J.W.; Nikolaidis, E.; Andersen, B.; Afjeh, A. Wind energy: Trends and enabling technologies. Renew. Sustain. Energy Rev. 2016, 53, 209-224. [CrossRef]

5. Zheng, B.; Xu, J.; Ni, T.; Li, M. Geothermal energy utilization trends from a technological paradigm perspective. Renew. Energy 2015, 77, 430-441. [CrossRef]

6. Li, K.; Bian, H.; Liu, C.; Zhang, D.; Yang, Y. Comparison of geothermal with solar and wind power generation systems. Renew. Sustain. Energy Rev. 2015, 42, 1464-1474. [CrossRef]

7. Na, J.; Kim, J.; Park, C.; Kim, E. TiO 2 nanoparticulate-wire hybrids for highly efficient solid-state dye-sensitized solar cells using SSP-PEDOTs. Rsc Adv. 2014, 4, 44555-44562. [CrossRef]

8. Pramanik, M.; Tsujimoto, Y.; Malgras, V.; Dou, S.X.; Kim, J.H.; Yamauchi, Y. Mesoporous iron phosphonate electrodes with crystalline frameworks for lithium-ion batteries. Chem. Mater. 2015, 27, 1082-1089. [CrossRef]

9. Hwang, S.M.; Lim, Y.-G.; Kim, J.-G.; Heo, Y.-U.; Lim, J.H.; Yamauchi, Y.; Park, M.-S.; Kim, Y.-J.; Dou, S.X.; Kim, J.H. A case study on fibrous porous $\mathrm{SnO}_{2}$ anode for robust, high-capacity lithium-ion batteries. Nano Energy 2014, 10, 53-62. [CrossRef]

10. Xue, H.; Zhao, J.; Tang, J.; Gong, H.; He, P.; Zhou, H.; Yamauchi, Y.; He, J. High-Loading $\mathrm{Nano}^{-S n O} \mathrm{~S}_{2}$ Encapsulated in situ in Three-Dimensional Rigid Porous Carbon for Superior Lithium-Ion Batteries. Chem. Eur. J. 2016, 22, 4915-4923. [CrossRef]

11. Huang, H.S.; Chang, K.H.; Suzuki, N.; Yamauchi, Y.; Hu, C.C.; Wu, K.C.W. Evaporation-Induced Coating of Hydrous Ruthenium Oxide on Mesoporous Silica Nanoparticles to Develop High-Performance Supercapacitors. Small 2013, 9, 2520-2526. [CrossRef] [PubMed]

12. Bastakoti, B.P.; Huang, H.-S.; Chen, L.-C.; Wu, K.C.-W.; Yamauchi, Y. Block copolymer assisted synthesis of porous $\alpha-\mathrm{Ni}(\mathrm{OH})_{2}$ microflowers with high surface areas as electrochemical pseudocapacitor materials. Chem. Commun. 2012, 48, 9150-9152. [CrossRef] [PubMed]

13. Makino, S.; Yamauchi, Y.; Sugimoto, W. Synthesis of electro-deposited ordered mesoporous $\mathrm{RuO}_{\mathrm{x}} \mathrm{using}$ lyotropic liquid crystal and application toward micro-supercapacitors. J. Power Sour. 2013, 227, 153-160. [CrossRef]

14. Eddaoudi, M.; Kim, J.; Rosi, N.; Vodak, D.; Wachter, J.; O’Keeffe, M.; Yaghi, O.M. Systematic design of pore size and functionality in isoreticular MOFs and their application in methane storage. Science 2002, 295, 469-472. [CrossRef]

15. Stock, N.; Biswas, S. Synthesis of metal-organic frameworks (MOFs): Routes to various MOF topologies, morphologies, and composites. Chem. Rev. 2011, 112, 933-969. [CrossRef]

16. Maurin, G.; Serre, C.; Cooper, A.; Férey, G. The new age of MOFs and of their porous-related solids. Chem. Soc. Rev. 2017, 46, 3104-3107. [CrossRef]

17. Tang, J.; Yamauchi, Y. Carbon materials: MOF morphologies in control. Nat. Chem. 2016, 8, 638-639. [CrossRef]

18. Zhang, W.; Jiang, X.; Zhao, Y.; Carné-Sánchez, A.; Malgras, V.; Kim, J.; Kim, J.H.; Wang, S.; Liu, J.; Jiang, J.-S. Hollow carbon nanobubbles: Monocrystalline MOF nanobubbles and their pyrolysis. Chem. Sci. 2017, 8, 3538-3546. [CrossRef]

19. Wang, C.; Kaneti, Y.V.; Bando, Y.; Lin, J.; Li, J.; Yamauchi, Y. Metal-organic framework-derived one-dimensional porous or hollow carbon-based nanofibers for energy storage and conversion. Mater. Horiz. 2018, 5, $394-407$. [CrossRef]

20. Torad, N.L.; Li, Y.; Ishihara, S.; Ariga, K.; Kamachi, Y.; Lian, H.-Y.; Hamoudi, H.; Sakka, Y.; Chaikittisilp, W.; $\mathrm{Wu}$, K.C.-W. MOF-derived nanoporous carbon as intracellular drug delivery carriers. Chem. Lett. 2014, 43, 717-719. [CrossRef]

21. Zhang, W.; Jiang, X.; Wang, X.; Kaneti, Y.V.; Chen, Y.; Liu, J.; Jiang, J.S.; Yamauchi, Y.; Hu, M. Spontaneous Weaving of Graphitic Carbon Networks Synthesized by Pyrolysis of ZIF-67 Crystals. Angew. Chem. Int. Ed. 2017, 56, 8435-8440. [CrossRef] [PubMed]

22. Young, C.; Salunkhe, R.R.; Tang, J.; Hu, C.-C.; Shahabuddin, M.; Yanmaz, E.; Hossain, M.S.A.; Kim, J.H.; Yamauchi, Y. Zeolitic imidazolate framework (ZIF-8) derived nanoporous carbon: The effect of carbonization temperature on the supercapacitor performance in an aqueous electrolyte. Phys. Chem. Chem. Phys. 2016, 18, 29308-29315. [CrossRef] [PubMed]

23. Salunkhe, R.R.; Young, C.; Tang, J.; Takei, T.; Ide, Y.; Kobayashi, N.; Yamauchi, Y. A high-performance supercapacitor cell based on ZIF-8-derived nanoporous carbon using an organic electrolyte. Chem. Commun. 2016, 52, 4764-4767. [CrossRef] [PubMed] 
24. Park, K.S.; Ni, Z.; Côté, A.P.; Choi, J.Y.; Huang, R.; Uribe-Romo, F.J.; Chae, H.K.; O’Keeffe, M.; Yaghi, O.M. Exceptional chemical and thermal stability of zeolitic imidazolate frameworks. Proc. Natl. Acad. Sci. USA 2006, 103, 10186-10191. [CrossRef]

25. Ameloot, R.; Gobechiya, E.; Uji-i, H.; Martens, J.A.; Hofkens, J.; Alaerts, L.; Sels, B.F.; De Vos, D.E. Direct patterning of oriented metal-organic framework crystals via control over crystallization kinetics in clear precursor solutions. Adv. Mater. 2010, 22, 2685-2688. [CrossRef]

26. Kim, J.; Young, C.; Lee, J.; Park, M.-S.; Shahabuddin, M.; Yamauchi, Y.; Kim, J.H. CNTs grown on nanoporous carbon from zeolitic imidazolate frameworks for supercapacitors. Chem. Commun. 2016, 52, 13016-13019. [CrossRef]

27. Kaneti, Y.V.; Tang, J.; Salunkhe, R.R.; Jiang, X.; Yu, A.; Wu, K.C.W.; Yamauchi, Y. Nanoarchitectured design of porous materials and nanocomposites from metal-organic frameworks. Adv. Mater. 2017, 29, 1604898. [CrossRef]

28. Kim, J.; Young, C.; Lee, J.; Heo, Y.-U.; Park, M.-S.; Hossain, M.S.A.; Yamauchi, Y.; Kim, J.H. Nanoarchitecture of MOF-derived nanoporous functional composites for hybrid supercapacitors. J. Mater. Chem. A 2017, 5, 15065-15072. [CrossRef]

29. Torad, N.L.; Hu, M.; Ishihara, S.; Sukegawa, H.; Belik, A.A.; Imura, M.; Ariga, K.; Sakka, Y.; Yamauchi, Y. Direct synthesis of MOF-derived nanoporous carbon with magnetic Co nanoparticles toward efficient water treatment. Small 2014, 10, 2096-2107. [CrossRef]

30. Torad, N.L.; Hu, M.; Kamachi, Y.; Takai, K.; Imura, M.; Naito, M.; Yamauchi, Y. Facile synthesis of nanoporous carbons with controlled particle sizes by direct carbonization of monodispersed ZIF-8 crystals. Chem. Commun. 2013, 49, 2521-2523. [CrossRef]

31. Chaikittisilp, W.; Hu, M.; Wang, H.; Huang, H.-S.; Fujita, T.; Wu, K.C.-W.; Chen, L.-C.; Yamauchi, Y.; Ariga, K. Nanoporous carbons through direct carbonization of a zeolitic imidazolate framework for supercapacitor electrodes. Chem. Commun. 2012, 48, 7259-7261. [CrossRef] [PubMed]

32. Paulraj, A.R.; Kiros, Y. $\mathrm{La}_{0.1} \mathrm{Ca}_{0.9} \mathrm{MnO}_{3} / \mathrm{Co}_{3} \mathrm{O}_{4}$ for oxygen reduction and evolution reactions (ORER) in alkaline electrolyte. J. Solid State Electr. 2018, 22, 1697-1710. [CrossRef]

33. Tatykayev, B.; Donat, F.; Alem, H.; Balan, L.; Medjahdi, G.; Uralbekov, B.; Schneider, R. Synthesis of core/shell $\mathrm{ZnO} / \mathrm{rGO}$ nanoparticles by calcination of ZIF-8/rGO composites and their photocatalytic activity. ACS Omega 2017, 2, 4946-4954. [CrossRef] [PubMed]

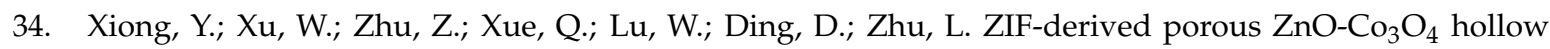
polyhedrons heterostructure with highly enhanced ethanol detection performance. Sens. Actuators B Chem. 2017, 253, 523-532. [CrossRef]

35. Zhuang, G.; Gao, Y.; Zhou, X.; Tao, X.; Luo, J.; Gao, Y.; Yan, Y.; Gao, P.; Zhong, X.; Wang, J. ZIF-67/COF-derived highly dispersed $\mathrm{Co}_{3} \mathrm{O}_{4} / \mathrm{N}$-doped porous carbon with excellent performance for oxygen evolution reaction and Li-ion batteries. Chem. Eng. J. 2017, 330, 1255-1264. [CrossRef]

36. Tuan, D.D.; Kun-Yi Andrew, L. ZIF-67-derived $\mathrm{Co}_{3} \mathrm{O}_{4}$ rhombic dodecahedron as an efficient non-noble-metal catalyst for hydrogen generation from borohydride hydrolysis. J. Taiwan Inst. Chem. Eng. 2018, 91, 274-280. [CrossRef]

(C) 2019 by the authors. Licensee MDPI, Basel, Switzerland. This article is an open access article distributed under the terms and conditions of the Creative Commons Attribution (CC BY) license (http://creativecommons.org/licenses/by/4.0/). 